\title{
Complete Nucleotide Sequence of the Cytochrome $b$ Gene of Channel Catfish Ictalurus punctatus and Comparison of Sequence Homology among Channel Catfish and Other Fishes
}

\author{
Taiki MATSUO ${ }^{1)}$, Yasuki OGAWA ${ }^{1)}$, Atsuo KUMAMARU ${ }^{2)}$, Kozo $\mathrm{OCHI}^{3)}$ and Yoshikazu ADACHI ${ }^{1) *}$ \\ 1) Animal Health Laboratory, School of Agriculture, Ibaraki University, 3-21-1 Ami, Ibaraki 300-0393, ') Ibaraki Prefectural Freshwater \\ Fisheries Experimental Station, 1560 Kou, Tamatsukuri, Ibaraki 311-3512 and ${ }^{3)}$ National Food Research Institute, 2-1-21 Kannondai, \\ Tsukuba, Ibaraki 305-8642
}

(Received 23 August 2000/Accepted 2 November 2000) ABSTRACT. To clarify the phylogenic relationship of channel catfish with other fishes, the cytochrome $b(C y t b)$ gene of the catfish was
cloned and sequenced. Channel catfish (Ictalurus punctatus) belonging to the family Ictaluridae in the order Siluriformes showed a $78.4-$
$87.4 \%$ similarity to all but one fish of the family Cyprinidae and river loach Crossostoma lacustre of the family Balitoridae in the order
Cypriniformes in which genes had already been sequenced, and a $97.2 \%$ similarity to the goldfish (Carassius auratus) belonging to the
family Cyprinidae. Within the family Cyprinidae, a $78.8-89.2 \%$ similarity to one another was recorded. In addition, the similarity rate
between the family Cyprinidae and the family Balitoridae reached a value of $77.8-79.9 \%$ in the order Cypriniformes. Furthermore, in
an unrooted phylogenetic tree consisting of four branches among eight fishes, channel catfish and goldfish appeared in the same branch.
These results suggested that the Cyt b gene of the channel catfish in the order Siluriformes was closely related to that of a goldfish in
the order Cypriniformes. The results were not agreement with the morphological classification. Genetic reclassification of the fishes may
be necessary to identify the ancestor. This is the first report on the cloning and complete sequencing the Cyt $b$ gene of the channel catfish
which may contribute to the genetic reclassification of catfishes belonging to the order Siluriformes.

KEY WORDS: channel catfish, cytochrome $b$ gene.

J. Vet. Med. Sci. 63(2): 207-210, 2001

Catfishes with various characteristics are known to consist of about 2,200 species and are widely distributed throughout the world. However, the catfishes have been classified only morphologically. On the other hand, although analyses of mitochondrial genes such as cytochrome $b(C y t b)$ and 16S ribosomal RNA genes of other fishes have been performed, there has been no report on the analysis of the complete sequences of the genes of the catfishes, unlike those of the genes in other fishes (the family Cyprinidae). Therefore, the evolutionary relationship between the catfishes and others fishes has not been determined. To address this problem, nucleotide sequence analyses of mitochondrial genes have been attempted. As a result, the complete nucleotide sequence of the $C y t b$ gene of the channel catfish (I. punctatus) were analyzed and the base arrangement between the catfish and other fishes was compared.

Total DNAs were isolated from the channel catfish ( $I$. punctatus) [6] propagated at the Ibaraki Prefectural Freshwater Fisheries Experimental Station and used as templates of PCR. Four primers synthesized according to the sequence of the Cyt $b$ gene of redfin shiner (Lythrurus umbratilis, accession no. U17274) were as follows: primer $\mathrm{A}^{\mathrm{FW}}$ (5'TGTAAAACGACGGCCAGTACCCGGATTCTA ACCGAGA3'), primer C ${ }^{\mathrm{RV}}$ (5'CCTCCAATCTTCGGATTAC3'), and primer $\mathrm{D}^{\mathrm{FW}}$ (5'TGTAAAACGACGGCCAG-

\footnotetext{
* Correspondence to: Adachi, Y., Animal Health Laboratory, School of Agriculture, Ibaraki University, 3-21-1 Ami, Ibaraki 300-0393, Japan.
}

TATGGCAAGCCTAGAAA3'). The TGTAAAACGACGGCCAGT of primers $\mathrm{A}^{\mathrm{FW}}, \mathrm{D}^{\mathrm{FW}}$ and $\mathrm{E}^{\mathrm{FW}}$, corresponding to $-21 \mathrm{M} 13$, was also used for direct sequence analyses of PCR fragments. The DNA fragment $\mathrm{D}^{\mathrm{FW}}-\mathrm{C}^{\mathrm{RV}}$ of the $C y t b$ gene of the channel catfish was amplified by using PCR consisting of incubation periods of $30 \mathrm{sec}$ at $94^{\circ} \mathrm{C}, 60 \mathrm{sec}$ at $50^{\circ} \mathrm{C}$, and $90 \mathrm{sec}$ at $72^{\circ} \mathrm{C}$ for 30 cycles after preincubation for 3 min at $94^{\circ} \mathrm{C}$ with primers $\mathrm{D}^{\mathrm{FW}}$ and $\mathrm{C}^{\mathrm{RV}}$ and Taq DNA polymerase (Takara-Shuzo Co., Kyoto, Japan). This PCR fragment was sequenced by using $-21 \mathrm{M} 13$ primer. Based on the sequencing results, primers $\mathrm{E}^{\mathrm{FW}}$ (5'TGTAAAACGACGGCCAGTGCATGATGAAACTTTGGCTCTC3') and $\mathrm{E}^{\mathrm{RV}}$ (5'GGACATTTGTCCTCATGGAAG3') were synthesized. The DNA fragments $A^{\mathrm{FW}}-\mathrm{E}^{\mathrm{RV}}, \mathrm{E}^{\mathrm{FW}}-\mathrm{C}^{\mathrm{RV}}$, and $\mathrm{E}^{\mathrm{FW}}-\mathrm{E}^{\mathrm{RV}}$ of the $C y t b$ gene of the channel catfish were amplified by using PCR: the fragment $\mathrm{A}^{\mathrm{FW}}-\mathrm{E}^{\mathrm{RV}}$ was amplified using incubation periods of $30 \mathrm{sec}$ at $94^{\circ} \mathrm{C}, 30 \mathrm{sec}$ at $50^{\circ} \mathrm{C}$, and $30 \mathrm{sec}$ at 74 ${ }^{\circ} \mathrm{C}$ for 25 cycles with primers $\mathrm{A}^{\mathrm{FW}}$ and $\mathrm{E}^{\mathrm{RV}}$ and KOD DNA polymerase (Toyobo, Tokyo, Japan); the fragment $\mathrm{E}^{\mathrm{FW}}-\mathrm{C}^{\mathrm{RV}}$ was amplified using incubation periods of $30 \mathrm{sec}$ at $94^{\circ} \mathrm{C}, 30$ sec at $67^{\circ} \mathrm{C}$, and $45 \mathrm{sec}$ at $74^{\circ} \mathrm{C}$ for 45 cycles with primers $\mathrm{E}^{\mathrm{FW}}$ and $\mathrm{C}^{\mathrm{RV}}$ and KOD DNA polymerase (Toyobo, Tokyo, Japan); and the fragment $\mathrm{E}^{\mathrm{FW}}-\mathrm{E}^{\mathrm{RV}}$ was amplified using incubation periods of $30 \mathrm{sec}$ at $94^{\circ} \mathrm{C}, 60 \mathrm{sec}$ at $50^{\circ} \mathrm{C}$, and $90 \mathrm{sec}$ at $72^{\circ} \mathrm{C}$ for 30 cycles after preincubation for $3 \mathrm{~min}$ at $94^{\circ} \mathrm{C}$ with primers $\mathrm{E}^{\mathrm{FW}}$ and $\mathrm{E}^{\mathrm{RV}}$ and Taq DNA polymerase (Takara-Shuzo Co., Kyoto, Japan). The resultant fragments were introduced into a pUC19 vector and sequenced on both sides by using a DSQ-1000L DNA sequencer (Shimadzu 


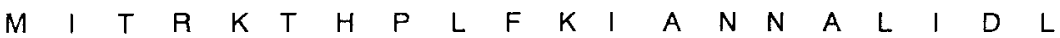
atg atc acc cga aaa acc cac ccg ctc ttc aaa att gce aac aat gca cta att gac cta

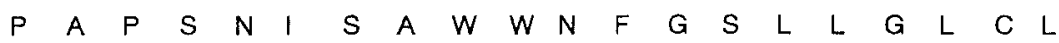
ccc goc cca tet aat atc tcc gca tga tga aac ttt gge tct cta cta gga tta tge tta

$\begin{array}{llllllllllllllllllll} & T & Q & \text { I } & L & T & G & L & F & L & A & M & H & Y & T & S & D & 1 & S & T\end{array}$ att act caa att cta acc gge cta ttt cta get ata cat tac acc tca gac att tca acc

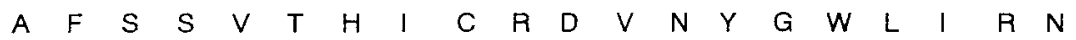
gca ttc tca tcc gtt acc cac atc tge cga gat gta aac tac gge tga cta att cgt aat

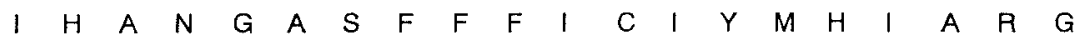
att cac gcc aat gga gca tca ttc ttc ttc atc tgt att tac ata cac att goc cga ggo

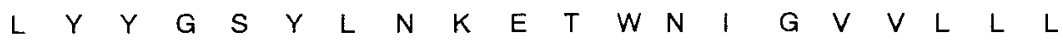
cta tat tat gga tca tac ett aac aaa gaa acc iga aac att gga gta gtt ctc cta ctc

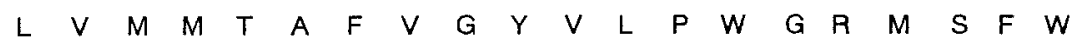
cta gtt ata atg aca goc ttt gtc ggt tat gtt ctt cca tga ggacga atg tcc ttt tga

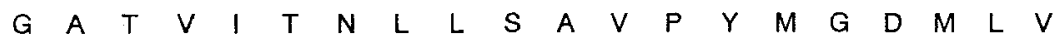
ggc get aca gta atc aca aac ctt cta tcc goc gtg cca tat ata gga gat ata tta gtt

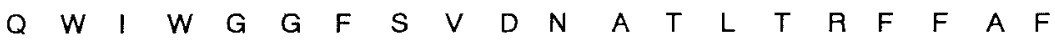
caa tga att tga gga ggg ttc tcc gta gac aat gca aca tta aca cga ttc ttt gca ttc

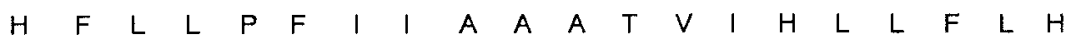
cac ttc cta cta cca ttc att atc gcc gcc gct act gtc att cac cta ctg ttl ctc cac

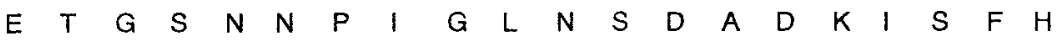
gaa aca gga tca aat aac ccc atc gga etg aac tca gac gca gac aaa att tet ttc cac

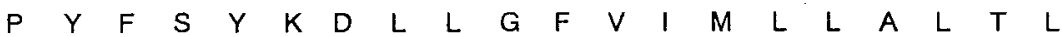
cca tac ttt tca tac aa gac ctc ctt ggg ttc gtg att ata cta cta gcc ctc aca ctc

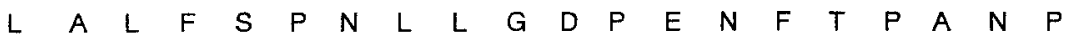
ctg gca tta ttc tcc cca aac ctt tta gga gac cca gaa aac ttc act cca gcc aat ccc

$\begin{array}{llllllllllllllllllllll}L & V & T & P & P & H & I & K & P & E & W & Y & F & L & F & A & Y & A & I & L\end{array}$ ctg gtt act ccc cet cac att aaa cca gag tga tat ttc ctg ttt gcc tac goc att ctc

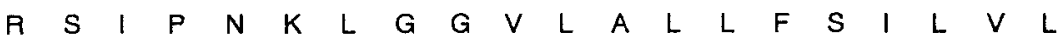
cga tca att ccc aac aaa cta gga gga gtt ctt gca cta cta ttc tcc atc ctc gta cta

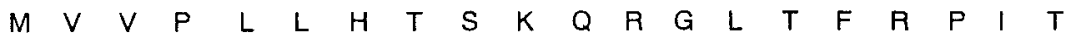
ata gtg gta ccc cta tta cat acc tca aaa caa cga gga cta acg ttc cgc ccc atc acc

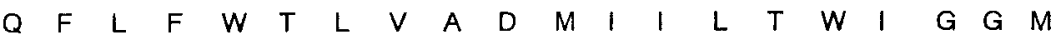
caa ttc cta ttt tga act cta gtc gca gac atg att atc atg aca'tga att gga gga ata

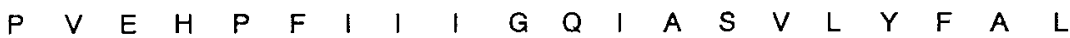
cca gta gaa cat cca ttc att atc atc gga caa atc gca tcc gtc cta tat ttc gca ctg

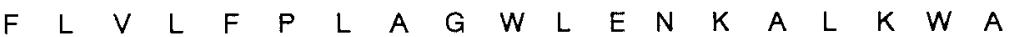
ttc ctt gtt ctc ttc cca cta gca gga tga tta gaa aat aaa gca ctg aaa tga gct

Fig. 1. DNA sequence and deduced amino acid sequence of the Cyt $b$ gene of the channel catfish. This sequence has been assigned the DDBJ accession number AB045119. 
Table 1. Comparison of the similarity of the complete sequence of the cytochrome $b$ gene among fishes ${ }^{\text {a) }}$

\begin{tabular}{|c|c|c|c|c|c|c|c|c|c|}
\hline \multirow[b]{5}{*}{ Fishes $^{\mathrm{b})}$} & \multicolumn{8}{|c|}{ Class Osteichthyes } & \multirow[b]{5}{*}{ Accession numbers } \\
\hline & \multirow{4}{*}{$\frac{\frac{\text { Order Siluriformes }}{\text { Family Ictaluridae }}}{\text { I. punctatus }}$} & \multicolumn{6}{|c|}{ Subclass Actinopterygii } & & \\
\hline & & \multicolumn{6}{|c|}{ Order Cypriniformes } & \multirow{3}{*}{$\frac{\text { Family Balitoridae }}{\text { C. lacustre }}$} & \\
\hline & & \multicolumn{6}{|c|}{ Family Cyprinidae } & & \\
\hline & & C. auratus & C. carpio & A. huegelii & $R$. ocellatus & B. barbus & L. umbratilis & & \\
\hline I. punctatus & 100 & 97.1 & 96.5 & 95.2 & 94.1 & 95.7 & 92.8 & 92.8 & AB045119 \\
\hline C. auratus & 97.2 & 100 & 96.8 & 94.5 & 93.2 & 95.0 & 92.6 & 92.9 & AF051858 \\
\hline C. carpio & 87.4 & 87.6 & 100 & 95.0 & 94.7 & 96.1 & 93.4 & 93.4 & X61010 \\
\hline A. huegelii & 84.9 & 85.4 & 87.7 & 100 & 92.9 & 98.2 & 92.1 & 93.1 & AF112133 \\
\hline R. ocellatus & 84.8 & 84.6 & 89.2 & 85.2 & 100 & 93.4 & 91.1 & 93.1 & AF051876 \\
\hline B. barbus & 84.0 & 84.1 & 86.5 & 89.0 & 85.0 & 100 & 92.1 & 93.7 & AF112123 \\
\hline L. umbratilis & 78.4 & 78.8 & 79.5 & 78.9 & 80.5 & 78.9 & 100 & 91.3 & U17274 \\
\hline C. lacustre & 79.6 & 79.5 & 81.5 & 79.0 & 79.9 & 79.4 & 77.8 & 100 & M91245 \\
\hline
\end{tabular}

a) The similarities (\%) of $C y t b$ genes at the levels of nucleotides and proteins predicted are shown in the left and right regions to a diagonal $100 \%$ line, respectively. b) I. punctatus, Ictalurus punctatus; C. auratus, Carassius auratus; C. carpio, Cyprinus carpio; A. huegelii, Aulopyge huegelii; R. ocellatus, Rhodeus ocellatus; B. barbus, Barbus barbus; L. umbratilis, Lythrurus umbratilis; C. lacustre, Crossostoma lacustre.

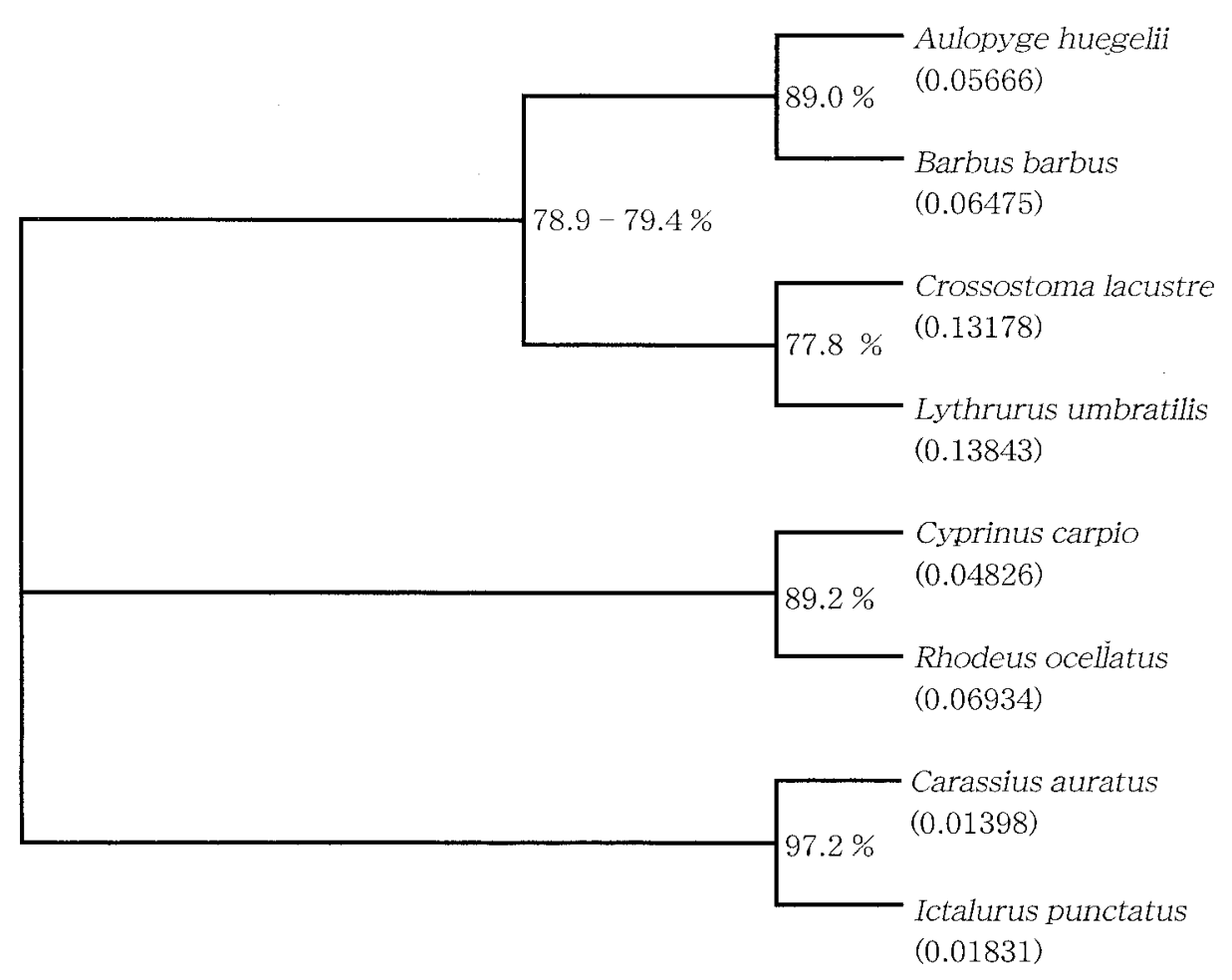

Fig. 2. Unrooted phylogenetic tree consisting of eight fishes. This tree was constructed by the neighborjoining method of Saitou and Nei [7] according to Kimura's modification [3]. Homology rates (\%) are indicated for each branch. Knuc value is shown in parentheses.

Co., Kyoto, Japan). The nucleotide sequences determined here were analyzed with GENETYX software (Software Development Co., Tokyo, Japan). The $C y t b$ gene of the channel catfish examined had 1140 nucleotide sequences encoding 380 amino acids (Fig. 1). The complete nucleotide sequence was registered with DDBJ (accession no. AB045119). DNA database search did not include information on the complete nucleotide sequences of $C y t b$ genes of the catfishes. The results of sequencing and search demonstrated that the Cyt $b$ base arrangement of the channel catfish
(I. punctatus) was closely related to that of the goldfish $(C$. auratus, accession no. AF051858). I. punctatus belongs to the family Ictaluridae in the order Siluriformes, while $C$. auratus belongs to the family Cyprinidae in the order Cypriniformes. These orders belong to the subclass Actinopterygii and the class Osteichthyes (Table 1). Although there are many reports on the $C y t b$ genes of the family Cyprinidae in terms of molecular phylogeny, there are only a few reports on those of other fishes. The $C y t b$ gene of the channel catfish was compared with that of other fishes in which 
complete sequences were analyzed (Table 1). The similarity among the genes in the fishes of the family Cyprinidae reached a value of 78.8 to $89.2 \%$. Similarity between the family Cyprinidae and the family Balitoridae belonging to the order Cypriniformes reached a value of 77.8 to $79.9 \%$. Channel catfish (I. punctatus) belonging to the family Ictaluridae in the order Siluriformes showed a $79.6 \%$ similarity to the river loach (Crossostoma lacustre, accession no. M91245) [9] belonging to the family Balitoridae in the order Cypriniformes. Channel catfish (I. punctatus) also showed a similarity value of 78.4 to $87.4 \%$ to the carp ( $C y p$ rinus carpio, accession no. X61010) [2], the dalmatian barbelgudgeon (Aulopyge huegelii, accession no. AF112133) [8], the rosy bitterling (Rhodeus ocellatus, accession no. AF051876) [4], Barbus barbus (accession no. AF11-2123) [1], and the redfin shiner (L. umbratilis) of the family Cyprinidae in the order Cypriniformes. However, the channel catfish (I. punctatus) belonging to the family Ictaluridae in the order Siluriformes showed the highest similarity $(97.2 \%)$ to the goldfish (C. auratus) of the family Cyprinidae in the order Cypriniformes, and the results were compatible with the amino acid sequence homology predicted (Table 1). Furthermore, evolutionary distances expressed by Knuc values were calculated as previously described [3] and an unrooted phylogenetic tree was drawn by the neighbor-joining method [7] (Fig. 2). Both channel catfish (I. punctatus) and goldfish (C. auratus) appeared in the fourth branch. These fishes were divided into four branches in a tree. The findings revealed that the Cyt $b$ gene of the channel catfish (I. punctatus) was most closely related to that of the goldfish (C. auratus) among those of several fishes previously reported. This fact indicates the existence of a dis- crepancy between genetic and morphological classifications. Therefore, it is important to identify the ancestor of the goldfish genetically. In general, the classification of fishes should be systematically performed based on information on various aspects. Our findings may provide some insight into the evolutionary relationship between the channel catfish and the other fishes. In particular, molecular analyses of the $C y t b$ gene could be important and more accurate for the classification.

ACKNOWLEDGMENTS. We thank Drs. T. Gamou and S. Kawamoto, National Food Research Institute, for their suggestions in preparation of the unrooted phylogenetic tree.

\section{REFERENCES}

1. Bianco, P. G. 1998. Ital. J. Zool. 65: 125-136.

2. Chang, Y. S., Huang, F. L. and Lo, T. B. 1994. J. Mol. Evol. 38: 138-155.

3. Kimura, M. 1980. J. Mol. Evol. 16: 111-120.

4. Kimura, S. and Nagata, Y. 1992. Jpn. J. Ichthyol. 38: 425429.

5. Kottelat, M., Whitten, A. J., Kartikasari, S. N. and Wirjoatmodjo, S. 1993. p. 221. In: Freshwater Fishes of Western Indonesia and Sulawesi (Kottelat, M., ed.), Periplus Editions, Hong Kong.

6. Page, L. M. and Burr, B. M. 1991. p. 432. In: A Field Guide to Freshwater Fishes: North America North of Mexico (Page, L. M. et al., eds.), Houghton Mifflin Company, Boston.

7. Saitou, N. and Nei, M. 1987. Mol. Biol. Evol. 4: 406-425.

8. Tsigenopoulos, C. S. and Berrebi, P. 2000. Mol. Phylogenet. Evol. 14: 165-179.

9. Tzeng, C. S., Hui, C. F., Shen, S. C. and Huang, P. C. 1992. Nucleic Acids Res. 20: 4853-4858. 